\title{
Asthma spreading and primary diagnostics problems in rural regions of Kazakhstan
}

\author{
Temyrzhan Nurpeissov, Tair Nurpeissov*, Gulzada Abdushukurova, Meruert Gazaliyeva, Aizhan Avdugalieva, \\ Alima Shagiyeva \\ From 2nd International Severe Asthma Forum (ISAF) \\ Athens, Greece. 13-15 November 2014
}

\section{Background}

In spite of all efforts, prevalence of bronchial asthma is growing steadily. However, its real level is often much higher than the official statistics.

The aim of this study was to assess the real prevalence of asthma using our innovational algorithm.

\section{Methods}

Screening study amongst the population of two villages of two different rural regions was conducted. 1204 patients became subjects. 681 women and 523 men, their age between 16 and 79 (average 41.3 \pm 4.17 ). During the first stage of the study, they underwent meticulous survey and peak expiratory flow measurement. In the second phase of the study, we examined patients of the study group with the use of an algorithm of asthma management developed by our team. It is a step-by-step strategy, created for general practitioners and medical assistants. This algorithm was designed to facilitate the early detection of asthma.

\section{Results}

According to official statistics, prevalence of asthma in Kazakhstan is $0.3 \%$ ( 3 cases per 1,000 population). However, even the first findings - results of our survey doubled this figure. Moreover, the implementation of our algorithm showed that real occurrence of asthma is $1.6 \%$ (16 cases per 1,000 population). Also, new data acquired suggests that more than half patients with COPD or obstructive bronchitis diagnoses actually has asthma.

\section{Conclusions}

Real prevalence of asthma in Kazakhstan is 5.33 times higher than the official data, many patients was wrongfully

\footnotetext{
SRI of Cardiology and Internal Diseases, Republican Allergological Center,
} ALMATY, Kazakhstan

(c) 2015 Nurpeissov et al: licensee BioMed Central Ltd. This is an Open Access article distributed under the terms of the Creative Commons Attribution License (http://creativecommons.org/licenses/by/4.0), which permits unrestricted use, distribution, and reproduction in any medium, provided the original work is properly cited. The Creative Commons Public Domain Dedication waiver

diagnosed with COPD or obstructive bronchitis. Even conducting a simple survey, we were able to reveal as much new patients with asthma, as registered. Therefore, the official statistics and diagnostics asthma has clear shortcomings and is in urgent need of improvement.

Published: 23 March 2015

doi:10.1186/2045-7022-5-S2-P22

Cite this article as: Nurpeissov et al:: Asthma spreading and primary diagnostics problems in rural regions of Kazakhstan. Clinical and Translational Allergy 2015 5(Suppl 2):P22.
Submit your next manuscript to BioMed Central and take full advantage of:

- Convenient online submission

- Thorough peer review

- No space constraints or color figure charges

- Immediate publication on acceptance

- Inclusion in PubMed, CAS, Scopus and Google Scholar

- Research which is freely available for redistribution Submit your manuscript at
www.biomedcentral.com/submit C Biomed Central 